\title{
ARTICLE OPEN ENSO relationship to summer rainfall variability and its potential predictability over Arabian Peninsula region
}

\author{
Muhammad Adnan Abid ${ }^{1}$, Mansour Almazroui ${ }^{1}$, Fred Kucharski ${ }^{1,2}$, Enda O'Brien ${ }^{1}$ and Ahmed Elsayed Yousef ${ }^{1}$
}

The El Niño Southern Oscillation (ENSO) phenomenon is considered to be responsible for rainfall predictability in many regions. Some of its regional teleconnections, such as over the Arabian Peninsula in boreal summer (June-August) season, are not well studied. Therefore, in this paper, the relationship between the summer seasonal mean rainfall and ENSO is analyzed with the aid of a 15-member ensemble of simulations using the Saudi-King Abdulaziz University (KAU) Atmospheric Global Climate Model (AGCM) for the period 1981-2015. The southwestern peninsula rainfall is linked to the Sea Surface Temperature (SST) anomalies in the central-eastern pacific region. This relationship is established through an atmospheric teleconnection which shows upper-level convergence anomalies over the southern Arabian Peninsula compensating the central-eastern Pacific upper-level divergence anomalies for the warm ENSO phase, and vice-versa for the cold Phase. The upper-level convergence over the southern Arabian Peninsula leads to sinking motion, low-level divergence and consequently to reduced rainfall in the warm phase, while reverse happens in the cold phase. The correlation coefficient between the observed area-averged Niño3.4 index and a Southwestern Arabian Peninsula Rainfall Index (SARI) is -0.43 (statistically significant at $95 \%$ ). Overall, model shows a potential predictability (PP) of 0.53 for the SARI region. Predictability during El Niño is higher than during La Niña events. This is not only because of a stronger signal, but also noise reduction contributes to the increase of PP in El Niño compared to that of La Niña years.

npj Climate and Atmospheric Science (2018)1:20171 ; doi:10.1038/s41612-017-0003-7

\section{INTRODUCTION}

Regional rainfall prediction is important for the management of the regional water and agricultural resources, which is mainly modulated by the El Niño Southern Oscillation (ENSO) phenomenon. ${ }^{1,2}$ The Arabian Peninsula is a water scarce region, ${ }^{3}$ and rainfall there is infrequent, in particular in the boreal summer season (June-August). Therefore, the summer rainfall predictability is of significant importance for the regional socio-economic sectors. The Arabian Peninsula (AP) lies in between the South Asian and the African region, in which most of the rainfall happens between the months of November and April. This period is the wet season for the peninsula, ${ }^{4,5}$ during which ENSO modulates the rainfall. ${ }^{2,6}$ On the other hand, during the boreal summer season the peninsula receives considerably less rainfall. ${ }^{5}$ The summer rainfall over the peninsula is mainly an extension of the Sahel monsoon and is located over the mountain ranges along the Red Sea from Saudi Arabia to western Yemen. ${ }^{7,8}$ The ENSO-summer rainfall teleconnections are well studied for the Sahel ${ }^{8-10}$ which is to the west of the AP, and for the south Asian Summer Monsoon, east of the peninsula, ${ }^{11-15}$ but the Arabian summer rainfall is less investigated. Therefore, the current study provides an analysis of the ENSO-Arabian Peninsula summer rainfall teleconnection and the related Potential Predictability by using an Atmospheric Global Climate Model (AGCM).

The droughts in the Sahel are modulated by warm ENSO conditions in the central-eastern equatorial Pacific region. ${ }^{8}$ During warm conditions, rising motion in the central-eastern Pacific is compensated by sinking motion over the eastern Indian Ocean region. As a consequence, upper-level cyclonic and low-level anticyclonic circulation anomalies develop in the subtropical Atlantic and African region through Sverdrup balance. The lowlevel anticyclonic circulation anomaly induces low-level divergence and sinking motion. Such a response favors drought conditions in the Sahel region. ${ }^{10}$ A more thermodynamical mechanism shows that the Sahel rainfall response can be induced by upper-level warming and thus stabilization of tropical regions outside the ENSO region itself, particularly on the eastern, Kelvinwave side of the ENSO-induced equatorial eastern Pacific heating. ${ }^{16}$ The relationship between ENSO and Sahel rainfall shows decadal variability ${ }^{17-19}$ that has been strengthened after 1980s, due to the indirect impact of enhanced monsoonal trough and the decrease of the moisture advection over Western African region. ${ }^{9}$

ENSO also has a strong influence on the South Asian monsoon and is responsible for drought conditions in its warm phase. Landsea temperature contrast is considered to be responsible for the summer monsoon rainfall over the South Asian region. The highpressure over the Tibetan plateau is considered to be important for maintaining the land-sea temperature contrast in the Asian region through elevated heating. ${ }^{20}$ This land-sea contrast has weakened in recent decades due to Indian Ocean warming. ${ }^{21}$ Furthermore, the east-west gradient between the larger diabatic heating in the western Pacific region compared to that of the African and the South Atlantic region favors an upper-level anticyclonic circulation in addition to that due to the north-south contrast. Mostly, the east-west gradient is affected by longitudinal shifts of the diabatic heating in the central Pacific region. ${ }^{15,22,23}$

\footnotetext{
${ }^{1}$ Center of Excellence for Climate Change Research/Department of Meteorology, King Abdulaziz University, Jeddah, Saudi Arabia and ${ }^{2}$ Earth System Physics Section, The Abdus Salam International Centre for Theoretical Physics (ICTP), Trieste, Italy

Correspondence: Muhammad Adnan Abid (mabid@kau.edu.sa)
}

Received: 4 December 2016 Revised: 26 July 2017 Accepted: 3 August 2017

Published online: 09 January 2018 

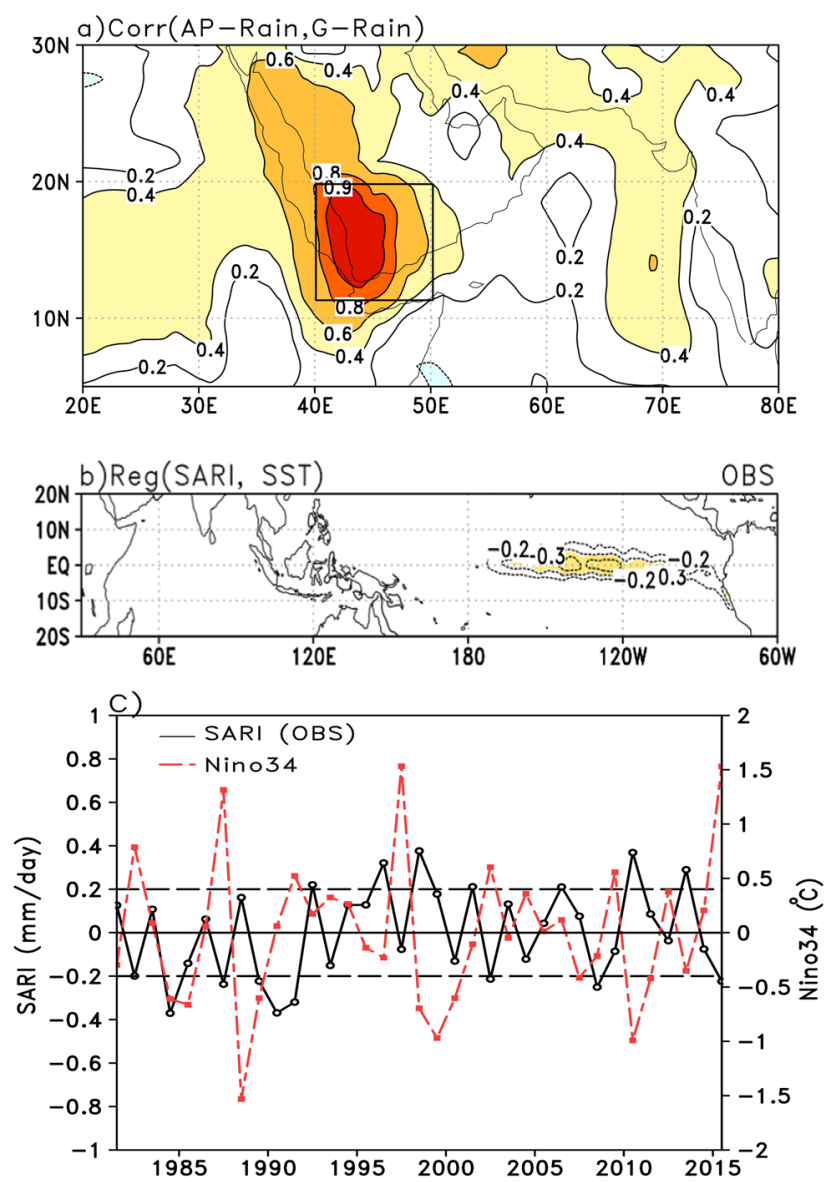

Fig. 1 a Correlation of the observed gridded Arabian Peninsula $\left[42: 45^{\circ} \mathrm{E} ; 12: 20^{\circ} \mathrm{N}\right]$ rainfall (only land region) on the global rainfall (GRain). b The Southwestern Arabian Peninsula rainfall index (SARI) averaged over $\left[40: 50^{\circ} \mathrm{E} ; 12: 20^{\circ} \mathrm{N}\right]$ shown as box in (a) is regressed onto the global Sea Surface Temperature for the period 1981-2015. Units are $\left({ }^{\circ} \mathrm{C}\right)$. Shaded region is statistically significant at $95 \%$ level. c Correlation of the SARI with Niño3.4 index for the period 1981-2015. One-Sigma standard deviation for SARI is shown as a dotted line

ENSO modifies the land-sea temperature contrast by inducing a tropospheric temperature gradient (which is weakened in its warm phase and strengthened in its cold phase ${ }^{24}$ ), and also through a modification of the Walker circulation. ${ }^{11,14,25,26}$ Both mechanisms contribute to a reduction of South Asian summer monsoon rainfall in the warm phase of ENSO and to an increase in its cold phase. Most recently, a similar teleconnection for the Ethiopian regional rainfall has been found which is to the south west of peninsula. ${ }^{7}$ However for the Arabian Peninsula, the ENSO teleconnection with its summer rainfall and the related predictability is not studied well, but is investigated in the current study.

The south and southwestern peninsula region receives most of the boreal summer (June-August) rainfall. The topography in the south and southwestern peninsula tends to favor low-level moisture convergence and consequent lifting if the flow configuration is favourable, which is a factor for precipitation formation in the region. ${ }^{27}$ However, the low-level divergent anomalies due to the descending Hadley cell and the existence of the Somali Jet over the southern peninsula tend to suppress the rainfall in the region. ${ }^{28}$ Most studies are conducted using observational datasets, and the details of the mechanism connecting summertime peninsula rainfall with ENSO are not explored. The current study investigates the summer rainfall mechanism in relationship with ENSO by using a 15-member ensemble of simulations with the Saudi-King Abdulaziz University (KAU) AGCM ${ }^{29}$ (see Methods). We also assessed the potential predictability of the model simulated rainfall in the Arabian Peninsula, which is important for local water and agriculture resources. The ensemble simulations can mimic the stochastic behavior of the atmosphere, and enable the separation of SST-forced signal from internal atmospheric variability (noise). ${ }^{30}$ Moreover, the European centre for mediumrange weather forecasts (ECMWF) seasonal prediction System4 (SYS4) dataset ${ }^{31}$ is used to compare regional rainfall PP simulated by the Saudi-KAU model. ${ }^{29}$

\section{RESULTS}

We analyze the spatial pattern of the observed and the model simulated ensemble mean summer rainfall climatology for the period 1981-2015, which shows that the model simulates the mean rainfall and its interannual variability quite well in comparison with observation (see Supplementary Fig. 1).

The south and southwestern Arabian Peninsula summer rainfall along the Red Sea masked over the land region $\left[42: 45^{\circ} \mathrm{E} ; 12: 20^{\circ} \mathrm{N}\right]$ is area-averaged and correlated with the global precipitation field for the period 1981-2015 and shown in Fig. 1a. The Southwestern Arabian Peninsula Rainfall Index (SARI) is defined as the areaaverage rainfall within the region $\left[40: 50^{\circ} \mathrm{E} ; 12: 20^{\circ} \mathrm{N}\right]$ found over the south and southwestern of the peninsula. The SARI region mainly includes south and southwestern Saudi Arabia, and Yemen region. The area-averaged observed rainfall over the SARI region is 24.3 $\mathrm{mm} / \mathrm{month}$ for the period 1981-2015. The standard deviation is $6.3 \mathrm{~mm} / \mathrm{month}$, while the coefficient of variability is $26 \%$ for the SARI domain. Figure $1 \mathrm{~b}$ shows the regression of SARI onto the global Sea Surface Temperature (SSTs) field. The maximum regression coefficient $(\sim-0.4)$ is found in the central eastern equatorial pacific region, which is the ENSO region. The negative relationship shows that the positive ENSO phase tends to suppress the rainfall in the region and vice-versa for cold phase. It is important to mention here that we also investigated the model simulated SARI teleconnection with ENSO and it reproduces quite well (not shown here) in comparison to the observation. Further, the area-averaged observed Niño3.4 index is negatively correlated $(-0.43)$ with the observed SARI for the period 1981-2015, which is statistically significant at the $95 \%$ significance level and shown in Fig. 1c. This shows that ENSO modulates the regional rainfall over the peninsula, favouring droughts in the region during the warm ENSO phase and wet conditions in the cold phase. A threshold of one standard deviation for the SARI shows, about $71 \%$ of drought years are induced by El Niño, and 38\% of the flood years by La Niña events. Moreover, the ensemble mean SARI simulated by the model is correlated with the observed SARI, which shows a modest rainfall correlation skill of 0.28 for the period 1981-2015. This is statistically significant at $90 \%$ significance level.

To understand the regional rainfall mechanism, the normalized SARI is regressed onto the observed and the model ensemble mean simulated 200-hPa velocity potential as shown in Fig. 2a, b, respectively. This shows SARI is mostly associated with positive velocity potential anomalies at upper levels in the central Pacific region, and negative anomalies over the Arabian region. This is the case for both model and observations, which shows that model is quite reasonable in producing the large-scale features. Figure $2 \mathrm{a}$, b suggests a link of SARI to the central-eastern Pacific, confirming that ENSO plays an important role in inducing the circulation anomalies responsible for rainfall variations in the southern AP region. Indeed, the cold phase of ENSO induces upper-level convergence in the central-eastern Pacific and the compensating upper-level divergence is located broadly in the Indian Ocean region, with maximum values encompassing the southern AP region and eastern Africa. ${ }^{15}$ Such an upper-level 

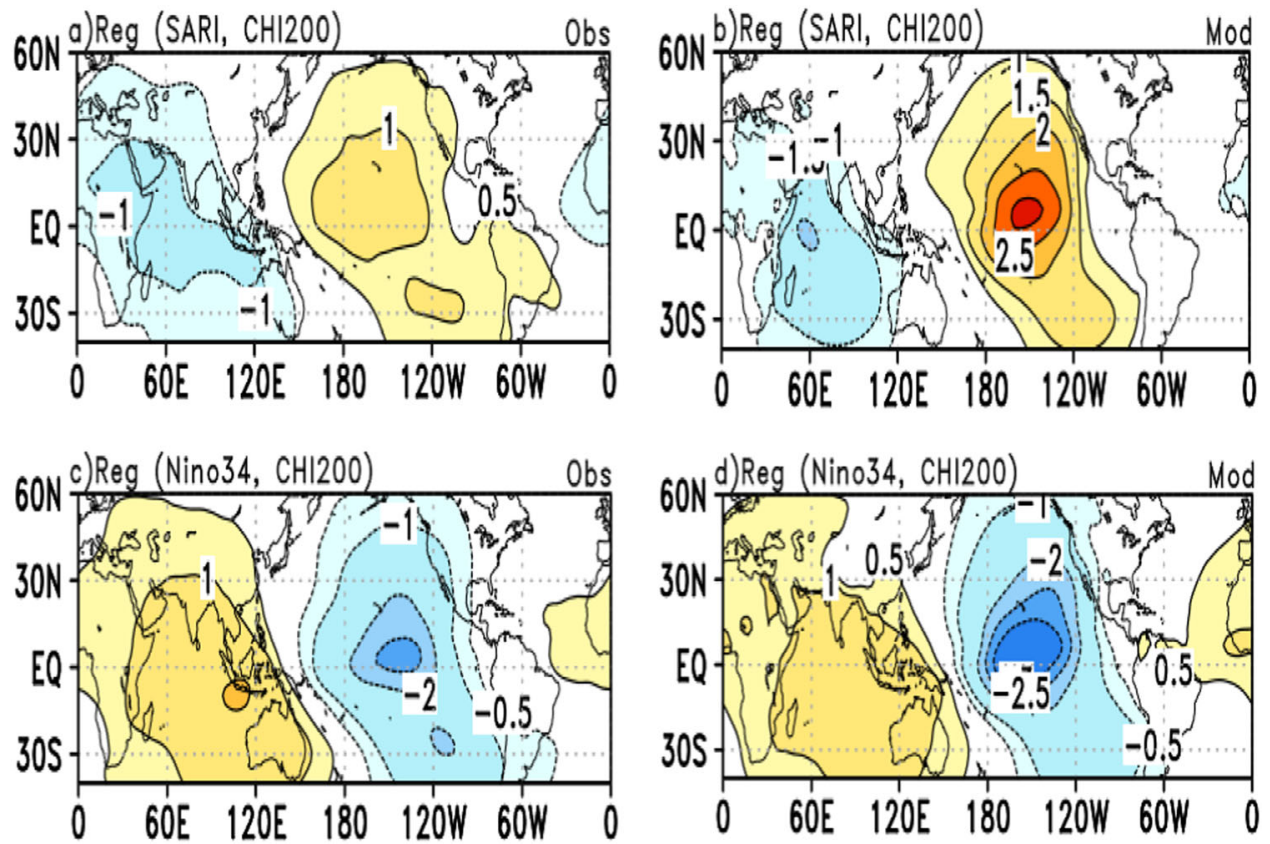

Fig. 2 a, b Regression of observed (Obs) and Saudi-KAU model (Mod) SARI onto the respective 200-hPa velocity Potential (Chi200); c, d Regression of Niño3.4 onto the observed and Model Velocity Potential (Chi200) respectively for the Period 1981-2015. Units for velocity potential is $1 . e^{+6} \times \mathrm{m}^{2} / \mathrm{sec}$. The shaded regions are at $95 \%$ significance level

divergence corresponds to rising motion and thus low-level convergence in the southern AP region. Further, the regression of normalized Niño3.4 index onto the observed and model ensemble mean simulated 200-hPa velocity potential as shown in Fig. 2c, d, respectively. This confirms the strong linkage of AP region upperlevel divergence with central-eastern Pacific upper-level convergence, and vice versa. These results are consistent with earlier findings on the South Asian and Sahel region and the adjoining east African region. ${ }^{7,10,15}$

Moreover, a total of three sensitivity experiments, are performed with the Saudi-KAU model to confirm this finding (see methods). Each experiment is run keeping its SST pattern fixed for 36-years, and changing only the initial conditions. A total of 35 ensemble members are analyzed, considering one year as a spin-up of the model. During the perpetual warm ENSO simulation, anomalous rising motion occurs in the central-eastern Pacific region, with subsidence over the Arabian and South Asian region. This sinking motion tends to reinforce the low-level divergence as shown in Fig. 3a, and the upper level convergence anomalies (not shown) over the region. This gradient is well supported by the east-west (convergence and divergence) anomalies as found in the velocity potential anomalies similar to that of Fig. 2c, d. Therefore, the rainfall is suppressed in the peninsula region in the warm ENSO phase as shown in Fig. 3b, and increased in the cold ENSO phase. The sinking motion tends to suppress the moisture, due to the lowlevel divergence in the SARI region and thus affects the regional rainfall, favouring drought conditions in the region. Overall, these sensitivity experiments confirm that ENSO modulates the rainfall in the Arabian Peninsula through atmospheric teleconnections. These results are also consistent with the earlier findings. ${ }^{10}$

Finally, we investigated the Potential Predictability (PP) of the Arabian Peninsula summer rainfall for the period 1981-2015. There are different measures for the PP; one is the Signal-to-Noise $(\mathrm{S} / \mathrm{N})$ ratio, while the other is the perfect model potential predictability (see methods). The signal variance represents the contribution of the external forcing while the noise variance is due to the internal atmospheric behavior. A maximum signal variance of 0.5 (Fig. 4a) is noted over the south and southwestern peninsula, while the noise variance (Fig. $4 \mathrm{~b}$ ) is almost twice as
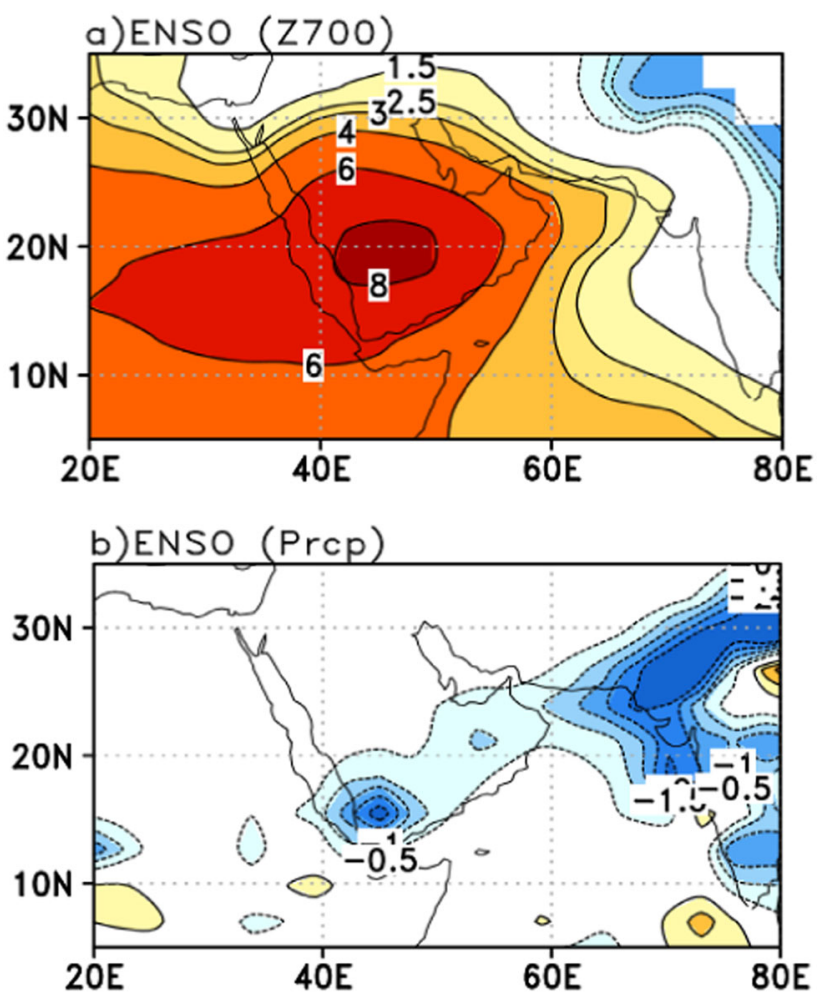

Fig. 3 ENSO anomalies for (a) 700-hPa geopotential height (Z700) with Units $(\mathrm{m})$, and (b) precipitation ( $\mathrm{mm} /$ day) from an idealized experiments

large as that of the signal variance. The $\mathrm{S} / \mathrm{N}$ ratio is shown in Fig. $4 c$, which has a maximum of 0.5 over the southwestern of the peninsula. Importantly, a much lower $\mathrm{S} / \mathrm{N}$ ratio is observed over the eastern African region and a significant predictability is found 

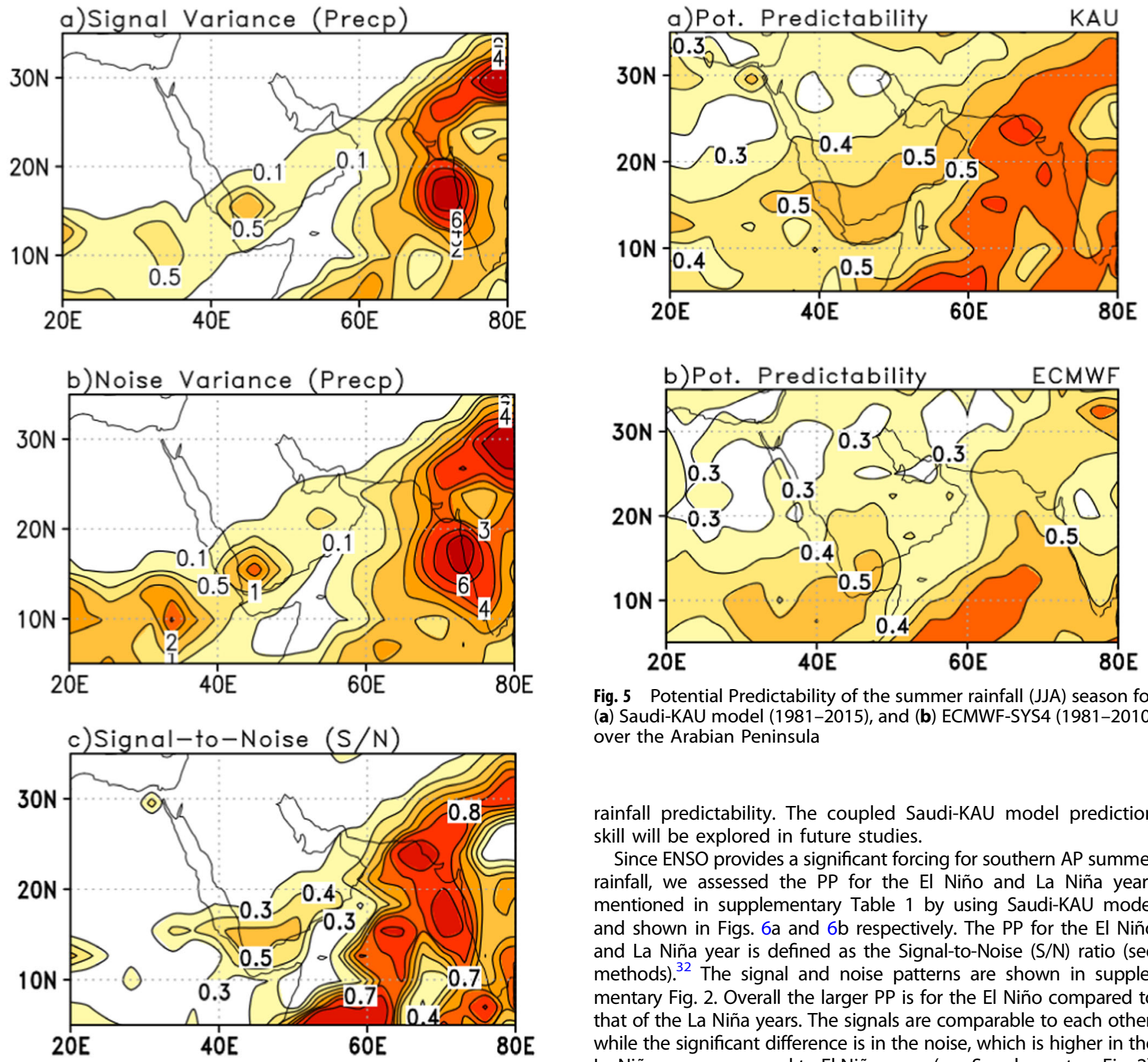

Fig. 5 Potential Predictability of the summer rainfall (JJA) season for (a) Saudi-KAU model (1981-2015), and (b) ECMWF-SYS4 (1981-2010) over the Arabian Peninsula

rainfall predictability. The coupled Saudi-KAU model prediction skill will be explored in future studies.

Since ENSO provides a significant forcing for southern AP summer rainfall, we assessed the PP for the El Niño and La Niña years mentioned in supplementary Table 1 by using Saudi-KAU model and shown in Figs. $6 \mathrm{a}$ and $6 \mathrm{~b}$ respectively. The PP for the El Niño and La Niña year is defined as the Signal-to-Noise $(\mathrm{S} / \mathrm{N})$ ratio (see methods). ${ }^{32}$ The signal and noise patterns are shown in supplementary Fig. 2. Overall the larger PP is for the El Niño compared to that of the La Niña years. The signals are comparable to each other, while the significant difference is in the noise, which is higher in the La Niña years compared to El Niño years (see Supplementary Fig. 2). The higher noise may be contributed by the larger rainfall variability among the La Niña years. This tends to limit the PP of La Niña years compared to that of El Niño years. The area-averaged PP over the SARI for the El Niño years is 0.86 , while for the La Niña is 0.27 . This shows that the PP in the El Niño years is about $65 \%$ higher over the SARI compared to that of La Niña years. Thus drier conditions, which may responsible for the droughts, are more predictable than the wetter conditions over the peninsula region.

by the ENSO. The higher noise variance compared to that of signal variance tends to reduce the predictability over the eastern African region. Further, the theoretical limit of the correlation skill, which is the perfect model PP, is assessed for the Saudi-KAU AGCM and the ECMWF-SYS4 and shown in Fig. 5. The PP of the Saudi-KAU model is in good agreement with the ECMWF-SYS4, which is considered a state-of-the-art seasonal prediction system. ${ }^{2}$ Although, the PP of the Saudi-KAU model is based on perfect boundary conditions, it is still worthwhile to compare it with ECMWF-SYS4 predictability. Both models show higher potential predictability in the southern AP region compared to other regions. The area-averaged PP of the SARI in the Saudi-KAU model is 0.53 ; this shows that this model is skilful to be used for regional

\section{DISCUSSION}

We found a negative significant relationship between the south and soutwestern Arabian Peninsula summer rainfall (SARI) and the ENSO. The physical mechanism for the ENSO influence on south and southwestern Arabian rainfall is an atmospheric teleconnection. ENSO modifies the Walker Circulation and leads to anomalous rising motion and upper-level divergence in its warm phase in the central-eastern tropical Pacific and vice-versa for the cold phase. During the warm phase, the upper-level divergence anomaly is compensated by upper-level convergence in the 

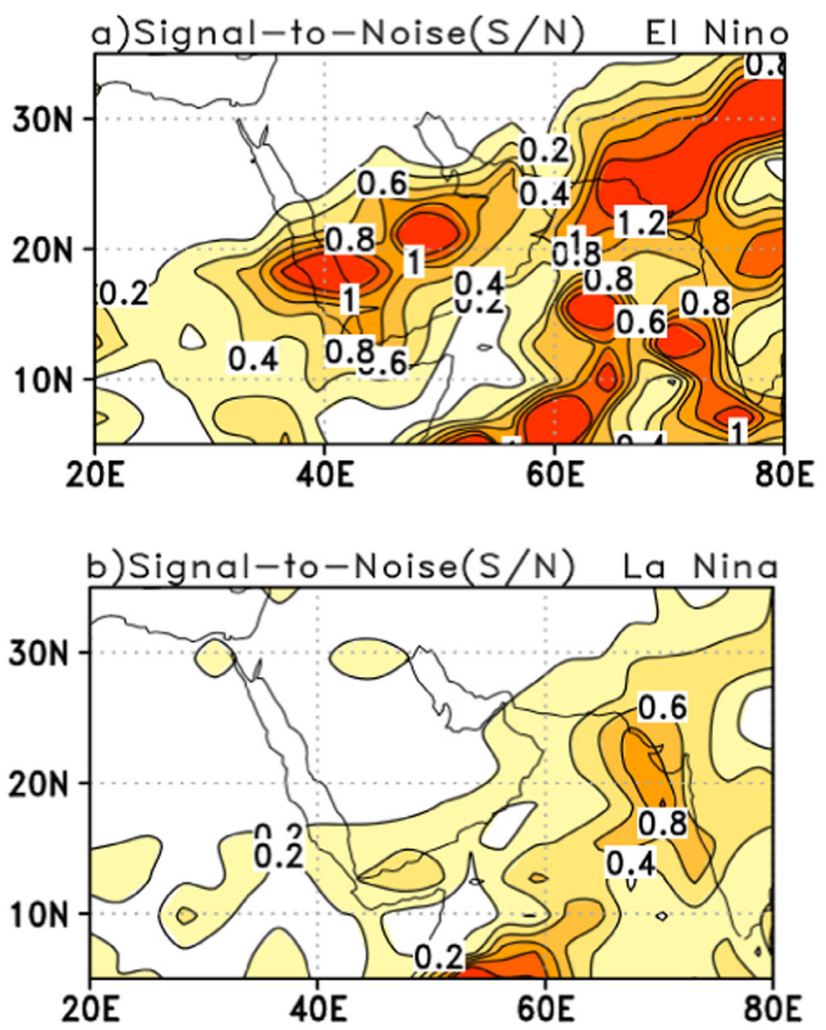

Fig. 6 Signal to noise ratio $(\mathrm{S} / \mathrm{N})$ of the summer rainfall over Arabian Peninsula for (a) El Niño, and (b) La Niña years

Indian Ocean region, with maxima over the southern Arabian Peninsula and eastern Africa. At low-levels the sinking motion in the southern Arabian region leads to low-level divergence and an anticyclonic circulation response. This response reduces rainfall in the south and southwestern Arabian region. The vice-versa happens for the cold ENSO phase. Importantly, the center of action for this atmospheric response is over the Arabian Peninsula, which also affects the regional rainfall predictability. This is also confirmed by the results of the idealized experiments.

Further, the rainfall PP simulated by the Saudi-KAU AGCM is comparable to the ECMWF-SYS4 seasonal prediction system. The Saudi-KAU model with perfect boundary conditions has a reasonable skill in predicting the rainfall over the SARI, which is comparable to that of ECMWF-SYS4 seasonal prediction system. Moreover, the Saudi-KAU model shows a higher PP in El Niño years compared to that of La Niña years over the SARI region, which shows that dry conditions are more predictable than the wetter conditions. This is mainly due to less noise during El Niño compared to that of La Niña years, which amplifies the predictability of the SARI region during EI Niño years, as compared to that of La Niña years. Overall Saudi-KAU AGCM is reasonably good in predicting the regional rainfall, which gives confidence that it can be used for the seasonal forecasting system. Although there is no perfect model, an improved representation of physical parameterization can reduce the biases, ${ }^{33}$ which may also lead to the better rainfall predictability. This aspect can be further explored in future studies. The rainfall prediction is important for the socioeconomic sectors such as water and agricultural resources and this study provides basis for the regional rainfall predictability.

\section{METHODS}

Following datasets, model and methods are used in the current study.
Datasets

The Global Precipitation Climatology Project (GPCP), ${ }^{34}$ which is the gridded observed global rainfall dataset of $2.5 \times 2.5$ degrees horizontal resolution from the National Centers for Environmental Prediction (NCEP)/National Center for Atmospheric Research (NCAR) is used in the current study for the period 1981-2015. Observed large-scale variables are also taken from NCEP/NCAR reanalysis. ${ }^{35}$ We also used observed reanalysis monthly Sea Surface temperature (SST) dataset of $1 \times 1$ degree from the Hadley Centre, United Kingdom. ${ }^{36}$

Further, the seasonal prediction dataset from the ECMWF-SYS4 ${ }^{31}$ for the period 1981-2010 is used to compare the Saudi-KAU model simulated Potential Predictability.

Model description and simulations

The Saudi-King Abdulaziz University (KAU) Atmospheric Global Climate Model (AGCM) is originally based on the Seoul National University (SNU) Global Climate Model (GCM) ${ }^{37}$ and has been adapted by KAU. ${ }^{29}$ The model spectral truncation horizontal resolution is T42 (corresponding to $128 \times 64$ horizontal grid-points) with 20 vertical sigma levels. Each ensemble member differs from the others only by its different initial atmospheric conditions based on the NCEP reanalysis dataset. ${ }^{38} 15$-member ensemble simulations are made with the Saudi-KAU AGCM by forcing each simulation with monthly varying SST and sea ice concentration dataset (HadISSTv1.1) from Hadley Center ${ }^{36}$ for the period 1980-2015. After a oneyear spin-up, data are analyzed for the period 1981-2015. The following configuration is adopted for Saudi-KAU model. The Simplified Arakawa Schubert (SAS) scheme is used as a convective parameterization, ${ }^{39,40}$ while a first order turbulence scheme based on the non-local and local closure is used as the boundary layer scheme. ${ }^{41}$ The land surface model is used to estimate the surface fluxes. ${ }^{42}$ The model also includes the nonprecipitating shallow convection scheme. ${ }^{43}$ Model includes the atmospheric radiation parameterization ${ }^{44}$ as well as a large scale parameterization scheme. ${ }^{45}$

Data analysis methods

Linear Regression analysis is used to identify the teleconnection patterns, by projecting the normalized time-series onto the required field variables. ${ }^{2}$ The two-tailed Student $t$-test is used to check the statistical significance.

The Potential Predictability (PP) of the AP summer rainfall is assessed for the period 1981-2015. The PP is assessed by the signal to noise ratio as well as by the theoretical limit of the correlation skill ${ }^{2}$. Signal variance is defined as the variance of the ensemble mean, while noise variance is defined as the mean of the variance of ensemble members from the ensemble mean. ${ }^{37,46,47}$ The signal to noise ratio provides a measure of the relative strength of contributions from external and internal atmospheric forcing, respectively, to overall variability within the ensemble. Mostly, the signal is influenced by external forcing i.e., SST anomalies, while the noise is generated by internal atmospheric variability, although sometimes internal variability can also contribute positively to the signal. ${ }^{32}$ However, the perfect model potential predictability is assessed, as the square root of the signal to the total variance, which is also known as the theoretical limit of the correlation skill. ${ }^{2}$ This shows that the model can achieve a maximum skill with perfect model and perfect boundary conditions. Further, we assessed the signal and noise for the El Niño and La Niña years. Here the signal is defined as the mean of the square of each year's ensemble mean anomaly, while noise is the variance over the ensemble members for the particular El Niño/La Niña year. ${ }^{32}$

\section{Sensitivity experiments}

A set of idealized experiments is designed to investigate the ENSO-rainfall teleconnection over the AP region. Total 3 sensitivity experiments are conducted: the first is the control with climatological SSTs; the second is with an El Niño composite added to the climatological SST in the tropical Pacific [160: $290^{\circ} \mathrm{E} ; 15^{\circ} \mathrm{S}: 15^{\circ} \mathrm{N}$ ] region; while a third is with a La Niña composite added to the climatological SSTs in the same region as that of El Niño run from June to August climatological SSTs only. The El Niño and La Niña composites are defined based on the years shown in Supplementary Table 1. 
Data availability statement

All observed reanalysis datasets are downloaded from their respective websites. The model data used in this study are available from the corresponding author on request.

\section{ACKNOWLEDGEMENTS}

The authors would like to thank the Director of the Center of the Excellence for Climate Change Research (CECCR), Deanship of the Graduate Studies (DGS) and the Deanship of the Scientific Research, King Abdulaziz University (KAU), Jeddah, Saudi Arabia for providing necessary support for this work. We would also like to thank the KAU High Performance Computing (HPC) Center (http://hpc.kau.edu.sa) for providing the Aziz Supercomputer as a computational resource for the current research work. The authors thank Franco Molteni for the ECMWF-SYS4 dataset. The authors would like to thank Editors (Chief and associate), the two anonymous reviewers for their useful suggestions that have improved the manuscript.

\section{AUTHOR CONTRIBUTIONS}

M.A.A. conducted the experimentation, analyzed the results and led the writing of this work. M.A.A., M.A. and F.K. discussed the initial thought about this work. M.A., F. $\mathrm{K}$. , and E.B contributed to the discussions and the writing. Some useful discussions are made with A.E.Y.

\section{ADDITIONAL INFORMATION}

Supplementary information accompanies the paper on the npj Climate and Atmospheric Science website (https://doi.org/10.1038/s41612-017-0003-7).

Competing interests: The authors declare no competing financial interests.

Publisher's note: Springer Nature remains neutral with regard to jurisdictional claims in published maps and institutional affiliations.

Change history: The original version of this Article had an incorrect Article number of 1 and an incorrect Publication year of 2017. These errors have now been corrected in the PDF and HTML versions of the Article.

\section{REFERENCES}

1. Wang, B., Lee, J. Y. \& Xiang, B. Asian summer monsoon rainfall predictability: a predictable mode analysis. Clim. Dyn. 44, 61-74 (2015).

2. Abid, M. A., Kucharski, F., Almazroui, M. \& Kang, I. S. Interannual rainfall variability and ECMWF-Sys4-based predictability over the Arabian Peninsula winter monsoon region. Q. J. R. Meteorol Soc. 142, 233-242, https://doi.org/10.1002/qj.2648 (2016).

3. Odhiambo, G.O. Water scarcity in the Arabian Peninsula and socio-economic implications. Appl. Water Sci. https://doi.org/10.1007/s13201-016-0440-1 (2016).

4. Almazroui, M. Calibration of TRMM rainfall climatology over Saudi Arabia during 1998-2009. Atmos. Res. 99, 400-414 (2011).

5. Almazroui, M., Abid, M. A., Athar, H., Islam, M. N. \& Ehsan, M. A. Interannual variability of rainfall over the Arabian Peninsula using the IPCC AR 4 Global Climate Models. Int. J. Climatol. 33, 2328-2340 (2013).

6. Kang, I. S., Rashid, I. U., Kucharski, F., Almazroui, M. \& Alkhalaf, A. A. Multidecadal Changes in the Relationship between ENSO and Wet-Season Precipitation in the Arabian Peninsula. J. Clim. https://doi.org/10.1175/JCLI-D-14-00388.1 (2015).

7. Gleixner, S., Keenlyside, N., Viste, E. et al. The El Niño effect on Ethiopian summer rainfall. Clim. Dyn. https://doi.org/10.1007/s00382-016-3421-z (2016).

8. Janicot, S., Moron, V. \& Fontaine, B. Sahel droughts and Enso dynamics. Geophys. Res. Lett. 23, 515-518 (1996).

9. Janicot, S., Trzaska, S. \& Poccard, I. Summer Sahel-ENSO teleconnection and decadal time scale SST variations. Clim. Dyn. 18, 303-320 (2001).

10. Rowell, D. P. Teleconnections between the tropical Pacific and the Sahel. Q. J. R. Meteorol. Soc. 127, 1683-1706 (2001).

11. Ju, J. \& Slingo, J. M. The Asian summer monsoon and ENSO. Q. J. R. Meteorol. Soc. 121, 1133-1168 (1995).

12. Krishna Kumar, K., Rajagopalan, B. \& Cane, M. A. On the weakening relationship between the Indian Monsoon and ENSO. Science 284, 2156-2159 (1999).

13. Krishna Kumar, K., Rajagopalan, B., Hoerling, M., Bates, G. \& Cane, M. A. Unraveling the mystery of Indian monsoon failure during El Niño. Science 314, 115-119 (2006).
14. Rasmusson, E. M. \& Carpenter, T. H. The relationship between the eastern Pacific sea surface temperature and rainfall over India and Sri Lanka. Mon. Weather Rev. 111, 517-528 (1983).

15. Kucharski, F., Bracco, A., Barimalala, R. \& Yoo, J. H. Contribution of the east-west thermal heating contrast to the South Asian Monsoon and consequences for its variability. Clim. Dyn. 37, 721-735 (2011).

16. Lintner, B. R. \& Chiang, J. C. H. Adjustment of the remote tropical climate to El Niño conditions. J. Clim. 20, 2544-2557 (2007).

17. Rodríguez-Fonseca, B. et al. Variability and Predictability of West African Droughts. A review on the role of Sea Surface Temperature Anomalies. J. Clim. https://doi.org/10.1175/JCLI-D-14-00130.1 (2015).

18. Losada, T. et al. Tropical SST and Sahel rainfall: a non-stationary relationship. Geophys. Res. Lett. 39, L12705, https://doi.org/10.1029/2012GL052423 (2012).

19. Mohino, E. et al. Changes in the interannual SST-forced signals on West African rainfall. AGCM intercomparison. Clim. Dyn. 37, 1707-1725 (2011).

20. Boos, W. \& Kuang, Z. Dominant control of the South Asian monsoon by orographic insulation versus plateau heating. Nature 463, 218-222 (2010).

21. Roxy, M. K. et al. Drying of Indian subcontinent by rapid Indian Ocean warming and a weakening land-sea thermal gradient. Nat. Comm. 6, 7423, https://doi.org/ 10.1038/ncomms842 (2015).

22. Chen, T.-C. Maintenance of summer Monsoon circulations: a planetary perspective. J. Clim. 16, 2022-2037 (2003).

23. Chou, C. Land-sea heating contrast in an idealized Asian summer monsoon. Clim. Dyn. 21, 11-25 (2003).

24. Goswami, B. N. \& Xavier, P. K. ENSO control on the south Asian monsoon through the length of the rainy season. Geophys. Res. Lett. 32, L18717, https://doi.org/ 10.1029/2005GL023216 (2005).

25. Goswami, B. N. Interannual variations of Indian summer monsoon in a GCM: external conditions versus internal feedbacks. J. Clim. 11, 501-521 (1998).

26. Webster, P. J. \& Yang, S. Monsoon and ENSO: selectively interactive systems. Q. J. R. Meteorol. Soc. 118, 877-926 (1992).

27. Abdullah, M. A. \& Almazroui, M. A. Climatological study of the southwestern region of Saudi Arabia. I. Rainfall analysis. Clim. Res. 9, 213-223 (1998).

28. Athar, H. \& Ammar, K. Seasonal characteristics of the large-scale moisture flux transport over the Arabian Peninsula. Theor. Appl. Climatol. 124, 565-578, https:// doi.org/10.1007/s00704-015-1437-7 (2016).

29. Almazroui, M. et al. Saudi-KAU coupled global climate model: description and performance. Earth Syst. Environ. 1:7, https://doi.org/10.1007/s41748-017-0009-7 (2017).

30. Ehsan, M. A., Kang, I. S., Almazroui, M., Abid, M. A. \& Kucharski, F. A quantitative assessment of changes in seasonal potential predictability for the twentieth century. Clim. Dyn. 41, 2697-2709 (2013).

31. Molteni, F. et al. The New ECMWF Seasonal Forecast System (System 4), Technical Memorandum 656. ECMWF: Reading, (2011).

32. Abid, M. A., Kang, I. S., Almazroui, M. \& Kucharski, F. Contribution of synoptic transients to the potential predictability of PNA circulation anomalies: El Niño versus La Niña. J. Clim. 28, 8347-8362 (2015).

33. Yang, Y. M., Kang, I. S. \& Almazroui, M. A mass flux closure function in a GCM based on the Richardson number. Clim. Dyn. 42, 1129-1138, https://doi.org/ 10.1007/s00382-014-2079-7 (2014).

34. Adler, R. F. et al. The Version 2 Global Precipitation Climatology Project (GPCP) Monthly Precipitation Analysis (1979-Present). J. Hydrometeor. 4, 1147-1167 (2003).

35. Kalnay et al. The NCEP/NCAR 40-year reanalysis project. Bull. Amer. Meteor. Soc. 77, 437-470 (1996).

36. Rayner, N. A. et al. Global analyses of SST, sea ice, and night marine air temperature since the late nineteenth century. J. Geophys. Res. 108, https://doi.org/ 10.1029/2002JD002670 (2003).

37. Kang, I. S., Lee, J. \& Park, C. Potential predictability of summer mean precipitation in a dynamical seasonal prediction system with systematic error correction. J. Clim. 17, 834-844 (2004).

38. Kanamitsu, M. et al. NCEP-DOE AMIP-II Reanalysis (R-2). Bull. Amer. Meteor. Soc. 83, 1631-1643 (2002).

39. Arakawa, A. \& Schubert, W. H. Interaction of a cumulus cloud ensemble with the large-scale environment, part I. J. Atmos. Sci. 31, 674-701 (1974).

40. Numaguti, A., Takahashi, M., Nakajima, T. \& Sumi, A. Development of an atmospheric general circulation model. In: Climate System Dynamics and Modelling (ed Matsuno, T). University of Tokyo, I-3, 1-27 (1995).

41. Holtslag, A. A. M. \& Boville, B. A. Local versus nonlocal boundary layer diffusion in a global climate model. J. Clim. 6, 1825-1842 (1993).

42. Bonan, G. B. The land surface climatology of the NCAR land surface model coupled to the NCAR community climate model. J. Clim. 11, 1307-1326 (1998). 
43. Tiedtke, M. The sensitivity of the time-mean large-scale flow to cumulus convection in the ECMWF model. 297-316 (1984).

44. Nakajima, T., Tsukamoto, M., Tsushima, Y. \& Numaguti, A. Modelling of the radiative process in an AGCM. In: Climate System Dynamics and Modelling (ed Matsuno, T). University of Tokyo, I-3, 104-123 (1995).

45. Le Treut, H. \& Li, Z. X. Sensitivity of an atmospheric general circulation model to prescribed SST changes: feedback effects associated with the simulation of cloud optical properties. Clim. Dyn. 5, 175-187 (1991).

46. Rowell, D. Assessing potential seasonal predictability with an ensemble of multidecadal GCM simulations. J. Clim. 11, 109-120 (1998).

47. Zwiers, F. W. Interannual variability and predictability in an ensemble of AMIP climate simulations conducted with the CCC GCM2. Clim. Dyn. 12, 825-848 (1996).
Open Access This article is licensed under a Creative Commons Attribution 4.0 International License, which permits use, sharing, adaptation, distribution and reproduction in any medium or format, as long as you give appropriate credit to the original author(s) and the source, provide a link to the Creative Commons license, and indicate if changes were made. The images or other third party material in this article are included in the article's Creative Commons license, unless indicated otherwise in a credit line to the material. If material is not included in the article's Creative Commons license and your intended use is not permitted by statutory regulation or exceeds the permitted use, you will need to obtain permission directly from the copyright holder. To view a copy of this license, visit http://creativecommons. org/licenses/by/4.0/.

(c) The Author(s) 2018 